\title{
Gastric non-secreting neuroendocrine tumor and hypochlorhydria-related hypergastrinemia: a case report
}

\author{
Marco Biolato ${ }^{1}$, Sergio Alfieri ${ }^{2}$, Gianluca laniro ${ }^{1}$, Marco Pizzoferrato ${ }^{1}$ and Giovanni Gasbarrini ${ }^{3 *}$
}

\begin{abstract}
Introduction: Zollinger-Ellison syndrome is characterized by recurrent peptic ulcers and diarrhea that result from gastrin-secreting neuroendocrine tumors of the gastrointestinal tract; nevertheless, severe hypergastrinemia may also have alternative pathogenetic explanations.

Case presentation: A 61-year-old woman of Caucasian origin presented with a history of epigastric pain and early satiety, severe hypergastrinemia (approximately $2000 \mathrm{pg} / \mathrm{mL}$ ) and a neuroendocrine polyp in the corpus of her stomach. Chronic atrophic gastritis and intestinal metaplasia was present, but she denied use of acid suppressant drugs and the results of tests for Helicobacter pylori as well as gastric parietal cell and intrinsic factor antibodies were negative. She underwent a radical gastric tangential resection. Six months later, serum gastrin was still elevated despite lack of recurrence of tumor.

Conclusion: The clinical picture was suggestive for a hypochlorhydria-related hypergastrinemia with subsequent development of a non-secreting carcinoid. We suggest a periodic endoscopic follow-up in patients with severe hypochlorhydria-related hypergastrinemia in order to earlier detect neuroendocrine polyps.
\end{abstract}

Keywords: Carcinoid, Gastric polyp, Gastrin, Gastrinoma, Zollinger-Ellison syndrome

\section{Introduction}

Initially described in 1955 [1], Zollinger-Ellison syndrome is characterized by multiple and recurrent peptic ulcers and persistent diarrhea that result from gastrinsecreting neuroendocrine tumors (gastrinomas) of the gastrointestinal tract [2]. Most gastrinomas are found in the pancreas, duodenum, or lymph nodes near the head of the pancreas, but they have also been found in other sites, and surgical resection is the antitumor treatment of choice [3]. Although both hypergastrinemia and histological features of neuroendocrine tumor are criteria for the diagnosis of Zollinger-Ellison syndrome, these data may also have an alternative pathogenetic explanation.

\section{Case presentation}

Here we report a case of a 61-year-old Italian woman of Caucasian origin who presented to our out-patient clinic

\footnotetext{
* Correspondence: studiogasbarrini@gasbarrini.it

${ }^{3}$ Fondazione Ricerca in Medicina ONLUS, Galleria Falcone e Borsellino 2, Bologna 40123, Italy

Full list of author information is available at the end of the article
}

with a three-month history of epigastric pain especially between meals, heartburn, early satiety and dyspepsia. The patient had a history of chronic lymphocytic thyroiditis, osteoporosis and small intestinal bacterial overgrowth. Her current medications included rifaximin, metronidazole and aluminum-magnesium hydroxide. The physical examination revealed a normal nutritional state. Laboratory tests revealed: serum gastrin $1900 \mathrm{pg} / \mathrm{mL}$ (reference range, 30-115), hemoglobin 11.6 g/dL (reference range, $12-16$ in women), vitamin B12 level $139 \mathrm{pg} / \mathrm{mL}$ (reference range, 158-600) and internationalized normalized ratio 1.34 (reference range 0.8-1.2); because of this, she started phytonadione $10 \mathrm{mg} /$ day. The results of other laboratory tests, including the white-cell count and the differential count, erythrocyte sedimentation rate, serum levels of electrolytes, glucose, total protein, albumin, globulin, cholesterol, lipids, folate, ferritin, amylase, lipase, renal function, liver function, thyroid function, serum neuron-specific enolase, chromogranin A, 5-hydroxy-indoloacetic acid, carcinoembryonic antigen, cancer antigen (CA) 19-9, CA 125, and gastric 

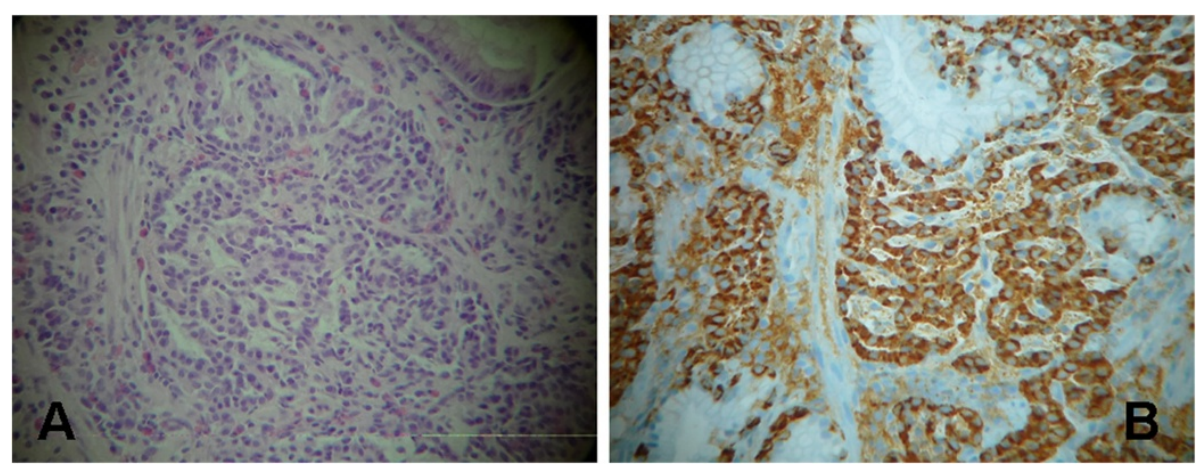

Figure 1 Hematoxylin and eosin staining $(\times 100)$ of gastric biopsy showed trabecular structures of small round-oval cells $(A)$; immunohistochemical staining $(\times 100)$ showed that the cytoplasm is positive for synaptophysin, which confirms the diagnosis of neuroendocrine carcinoma (B).

parietal cell and intrinsic factor antibodies, were normal. A urea breath test for Helicobacter pylori infection was negative. An upper gastrointestinal endoscopy was performed. A two-cm single sessile protruding-type polyp was found in the greater curvature of the patient's stomach. Microscopic examination showed clumps of small round-oval shaped cells with areas arranged in a trabecular or solid pattern in the gastric mucosa (Figure 1). There were no area of necrosis and the KI-67 index was $3 \%$. Immunohistochemical staining showed that the cancer cells were positive for neuron-specific enolase, cytokeratin and synaptophysin. The findings were those of a well-differentiated neuroendocrine carcinoma (carcinoid tumor). Mild chronic atrophic gastritis and intestinal metaplasia were present in the surrounding, non- neoplastic tissue in the corpus of her stomach. Thiazine staining for $\mathrm{H}$. pylori was negative. Total body computed tomography showed no evidence of lymph node or hepatic metastases and confirmed a hypervascular $1.7 \times 1.3 \mathrm{~cm}$ polyp in the stomach (Figure 2). The patient underwent a gastric tangential resection, restricted to the portion of corpus of gastric wall involved by tumor and sparing almost all of the stomach (Figure 3). Microscopic examination confirmed a well-differentiated, lowgrade, neuroendocrine tumor of the stomach infiltrating the submucosal layer with microvascular invasion. The margin of the resection was free of disease. Postoperative staging was pT1 according to the Union for International Cancer Control's TNM Classification of Malignant Tumours (7th edition). The patient's postoperative course

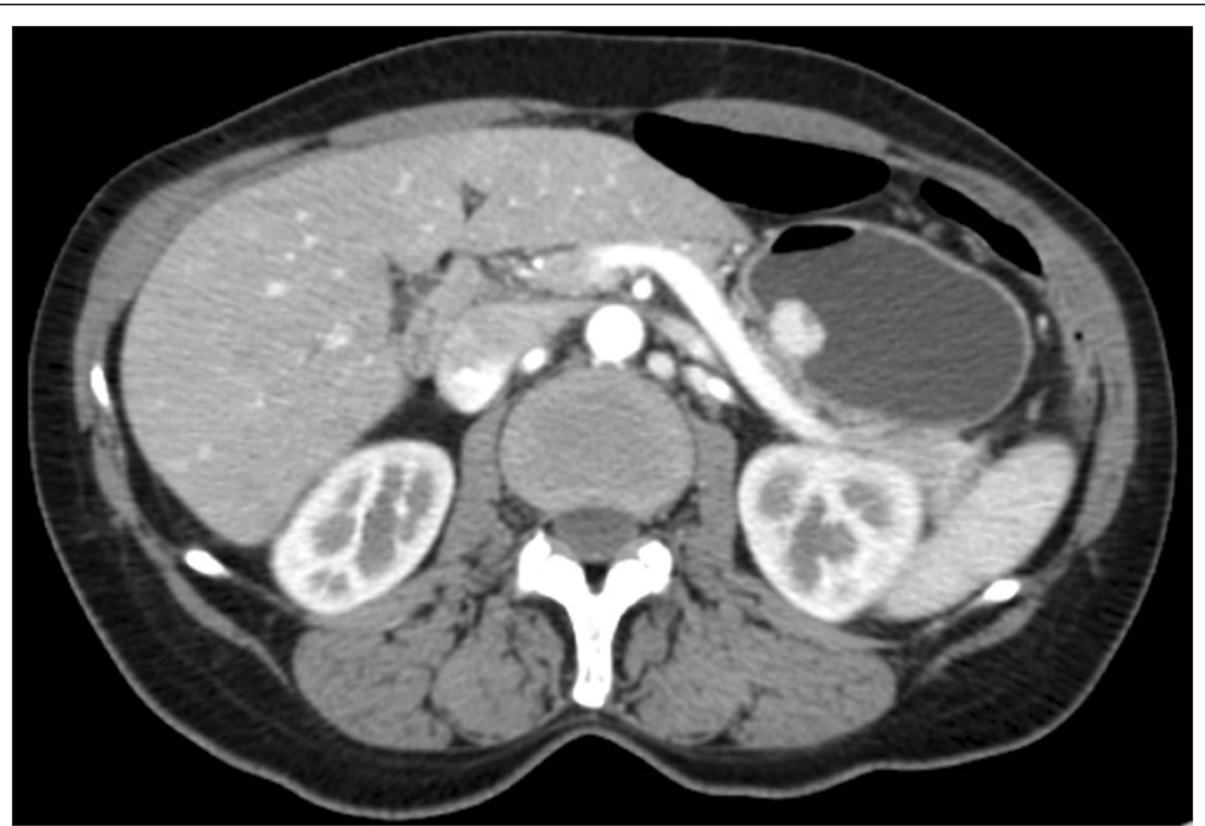

Figure 2 Abdomen computed tomography scan showed a gastric polyp with arterial enhancement and an apical area of necrosis. 


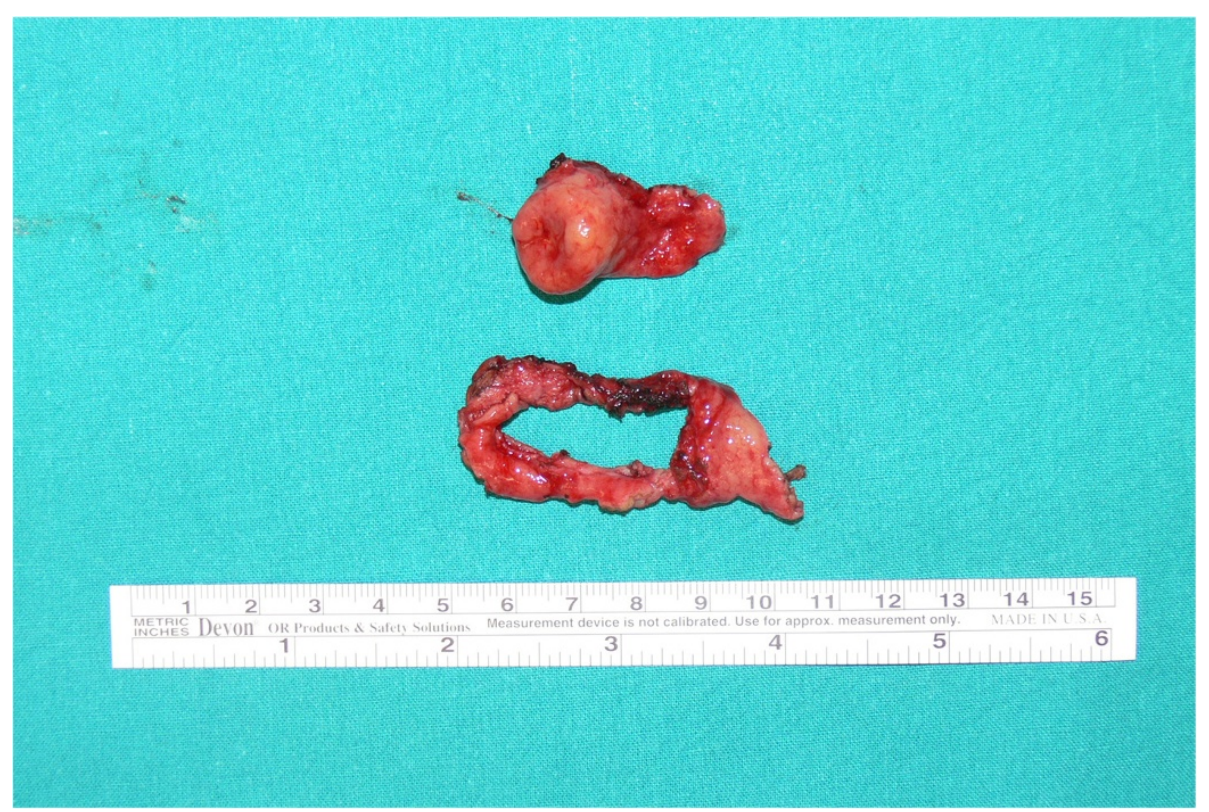

Figure $3 \mathrm{~A}$ gross photograph of the gastrectomy specimen showed a polyp (two $\mathrm{cm}$ in diameter) with an apical area of necrosis and the resected mucosal ring.

was uneventful and she remained in a good clinical condition. Six months later, her serum gastrin was $2011 \mathrm{pg} / \mathrm{mL}$. A total body computed tomography scan and an upper gastrointestinal endoscopy excluded recurrence of the disease. A gastric antral biopsy showed mild chronic atrophic gastritis and intestinal metaplasia. Staining for $H$. pylori was negative. Immunohistochemical staining for cytokeratin and synaptophysin showed mild hyperplasia of neuroendocrine gastric cells. No tumor recurrence was revealed.

\section{Discussion}

A severe $(>1000 \mathrm{pg} / \mathrm{mL})$ elevation of fasting serum gastrin concentration is usually suggestive for Zollinger-Ellison syndrome; on top of this, the use of acid suppressant medication (both proton pump inhibitors or H2-receptor antagonists), the presence of $H$. pylori infection and autoimmune achlorhydric atrophic gastritis without or with pernicious anemia may lead to mild-to-moderate hypergastrinemia $[4,5]$. In our case, the absence of symptoms of classical gastrinoma and the persistence of extremely elevated gastrin after radical tumor excision rule out the diagnosis of Zollinger-Ellison syndrome. The gastric biopsy performed six months after tumor resection showed chronic atrophic gastritis and intestinal metaplasia, with mild hyperplasia of antral G cells; this data, together with vitamin B12 deficiency anemia, suggest a hypochlorhydria-related hypergastrinemia. Although gastric parietal cell and intrinsic factor antibodies were both negative, cases of autoantibody-negative type A gastritis have been described [6]. More than 100 cases of gastric carcinoids in patients with pernicious anemia are described in the literature. Because the hormone gastrin regulates several important cellular processes in the gastric epithelium including proliferation, apoptosis, migration, invasion, tissue remodeling and angiogenesis [7], we hypothesize that the unusual and extremely elevated levels of gastrin facilitated the occurrence of gastric neuroendocrine tumor in this patient [8]. Some authors have suggested that small multiple gastric carcinoids associated with atrophic gastritis are indolent, despite patients having continuous hypergastrinemia $[9,10]$; notwithstanding, a surgical approach in tumors larger than two $\mathrm{cm}$ seems to be cautious.

\section{Conclusions}

We suggest a periodic endoscopic follow-up in patients with severe $(>1000 \mathrm{pg} / \mathrm{mL})$ hypochlorhydria-related hypergastrinemia in order to earlier detect neuroendocrine polyps.

\section{Consent}

Written informed consent was obtained from the patient for publication of this case report and accompanying images. A copy of the written consent is available for review by the Editor-in-Chief of this journal.

\section{Competing interests}

The authors declare that they have no competing interests.

\section{Authors' contributions}

MB wrote the paper, SA collected the images, GI and MP wrote the references and the figure captions, and GG revised the paper. All authors read and approved the final manuscript. 


\section{Author details}

'Institute of Internal Medicine, Catholic University, 'A. Gemelli' Hospital, Rome, Italy. ${ }^{2}$ Department of Digestive Surgery, Catholic University, 'A. Gemelli' Hospital, Rome, Italy. ${ }^{3}$ Fondazione Ricerca in Medicina ONLUS, Galleria Falcone e Borsellino 2, Bologna 40123, Italy

Received: 21 July 2012 Accepted: 8 November 2012

Published: 22 February 2013

\section{References}

1. Zollinger RM, Ellison EH: Primary peptic ulcerations of the jejunum associated with islet cell tumors of the pancreas. Ann Surg 1955, 142(2):709-723.

2. Ellison EC, Johnson JA: The Zollinger-Ellison syndrome: a comprehensive review of historical, scientific, and clinical considerations. Curr Probl Surg 2009, 46(1):13-106

3. Norton JA, Fraker DL, Alexander HR, Venzon DJ, Doppman IL, Serrano J Goebel SU, Peghini PL, Roy PK, Gibril F, Jensen RT: Surgery to cure the Zollinger-Ellison syndrome. N Engl J Med 1999, 341(9):635-644.

4. Murugesan SV, Varro A, Pritchard DM: Review article: Strategies to determine whether hypergastrinaemia is due to Zollinger-Ellison syndrome rather than a more common benign cause. Aliment Pharmacol Ther 2009, 29(10):1055-1068.

5. Melcescu E, Hogan RB II, Brown K, Boyd SA, Abell TL, Koch CA: The various faces of autoimmune endocrinopathies: Non-tumoral hypergastrinemia in a patient with lymphocytic colitis and chronic autoimmune gastritis. Exp Mol Pathol 2012, 93(3):434-440.

6. Lahner E, Norman GL, Severi C, Encabo S, Shums Z, Vannella L, Delle Fave G, Annibale B: Reassessment of intrinsic factor and parietal cell autoantibodies in atrophic gastritis with respect to cobalamin deficiency. Am J Gastroenterol 2009, 104(8):2071-2079.

7. Burkitt MD, Varro A, Pritchard DM: Importance of gastrin in the pathogenesis and treatment of gastric tumors. World J Gastroenterol 2009, 15(1):1-16

8. Hosokawa O, Kaizaki Y, Hattori M, Douden K, Hayashi H, Morishita M, Ohta K Long-term follow up of patients with multiple gastric carcinoids associated with type A gastritis. Gastric Cancer 2005, 8(1):42-46.

9. Itsuno M, Watanabe H, Iwafuchi M, Ito S, Yanaihara N, Sato K, Kikuchi M, Akiyama N: Multiple carcinoids and endocrine cell micronests in type A gastritis. Their morphology, histogenesis, and natural history. Cance 1989, 63(5):881-890

10. Rindi G, Luinetti O, Cornaggia M, Capella C, Solcia E: Three subtypes of gastric argyrophil carcinoid and the gastric neuroendocrine carcinoma: a clinicopathologic study. Gastroenterology 1993, 104(4):994-1006.

doi:10.1186/1752-1947-7-53

Cite this article as: Biolato et al:: Gastric non-secreting neuroendocrine tumor and hypochlorhydria-related hypergastrinemia: a case report. Journal of Medical Case Reports 2013 7:53.

\section{Submit your next manuscript to BioMed Central and take full advantage of:}

- Convenient online submission

- Thorough peer review

- No space constraints or color figure charges

- Immediate publication on acceptance

- Inclusion in PubMed, CAS, Scopus and Google Scholar

- Research which is freely available for redistribution 